\title{
IMPROVING THE STABILITY OF THE DIRECTIONAL ROOM G 31-33, HORIZON 210 - EAST, OCNELE MARI-COCENEȘTI SALT MINE, BY REINFORCEMENT WITH ANCHORS AND SHOTCRETE
}

\author{
Dacian-Paul MARIAN ${ }^{1 *}$, Ilie ONICA ${ }^{2}$ \\ ${ }^{1}$ University of Petroșani, Petroșani, Romania, dacianmarian@upet.ro \\ ${ }^{2}$ University of Petroșani, Petroșani, Romania, onicai2004@yahoo.com
}

DOI: $10.2478 /$ minrv-2021-0031

Keywords: rock salt, rooms and pillars mining, stability, reinforcement, anchors, shotcrete, displacement, numerical model, finite element.

Abstract: The rock salt deposit from Ocnele Mari - Cocenești was mined by the method with rooms and small square pillars, at the levels $+226 \mathrm{~m}$ and $+210 \mathrm{~m}$. Although the saline is not deep, certain instability phenomena (cracks, exfoliations) have occurred in the resistance structures (pillars, ceilings), especially in the G31-33 directional room, horizon 210E. These instability phenomena were also highlighted following the 3D finite element numerical modelling. In order to prevent the degradation of the mining excavations and the resistance structures, the affected surfaces were supported with anchors and reinforced shotcrete. The ceiling of the consolidated section of the G31-33 directional room, horizon 210E is monitored by the systematic measurement, on topographic landmarks mounted on the ceiling, of the vertical and horizontal displacements.

\section{Generalities}

The rock salt deposit from Ocnele Mari is located in the region of the sub-Carpathian hills of Oltenia, and Coceneşti perimeter is located in the eastern part of Ocnele Mari deposit (fig.1).

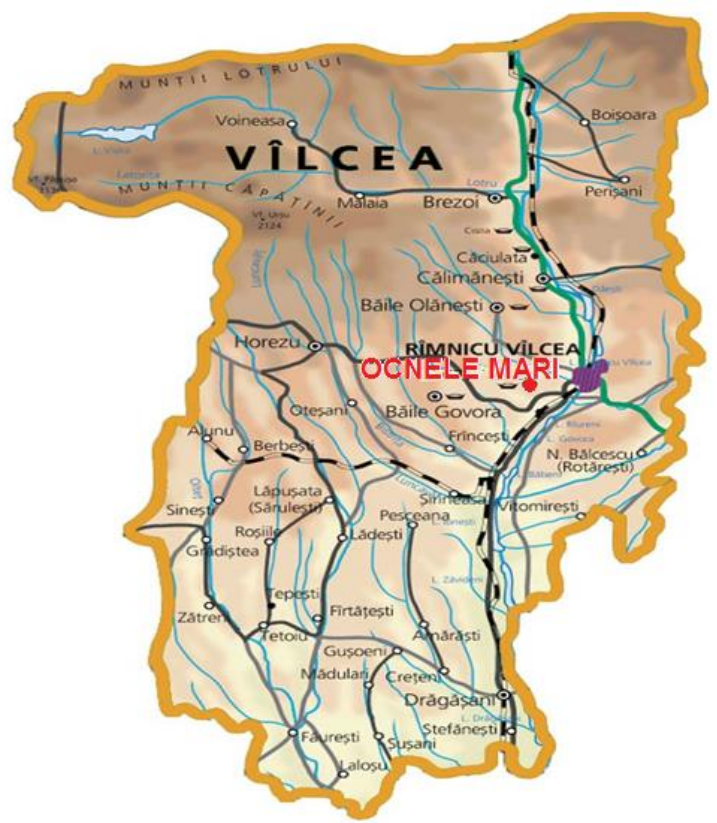

Figure 1. Geographical location of the deposit of rock salt Ocnele Mari [1]

\footnotetext{
* Corresponding author: Dacian-Paul Marian, Assoc.Prof. PhD. Eng., University of Petroșani, Petroșani, Romania, contact details (University st. no. 20, Petroșani, Romania dacianmarian@upet.ro)
} 
From a geomorphological point of view, the relief is hilly to the north, west and east, in the south the region is open to the depression of Rm. Vâlcea - Horezu. The hilly relief has heights between $260-500 \mathrm{~m}$, predominating the heights between $350-450 \mathrm{~m}$.

Ocnele Mari region, where the deposit is located, belongs to the Getic Depression, which is the outermost unit of the Southern Carpathians.

The rock salt was formed in a halogen basin consisting of a suite of bays and lagoons. The salt deposition took place unevenly inside the basin, depending on the feeding conditions and the morphology of the bottom of the sedimentation basin, the age of the rock salt from Ocnele Mari - Cocenești being the middle Badenian.

The sedimentary formations of Ocnele Mari region correspond to the Paleogene - Quaternary interval. The sedimentation process that began in the Paleogene was not continued, with many discontinuities in this process.

From a stratigraphic point of view, the Ocnele Mari region includes Paleogene, Neogene and Quaternary geological formations.

The horizon with rock salt deposits is presented in a lagoon facies, with local distribution, being formed by salt massifs, gypsum and salty marls, in this horizon being included also the rock salt deposit from Ocnele Mari, and the salt massif appears in the axial lifting area from Ocniţa - Ocnele Mari.

The salt deposit from Ocnele Mari has the shape of an elongated lens in the E-W direction, measuring in this sense approx. $7.5 \mathrm{~km}$, and to the N-S, approx. $3.5 \mathrm{~km}$, showing an axial elevation in Ocnita area, with slopes to the $\mathrm{N}$ (fig. 2).

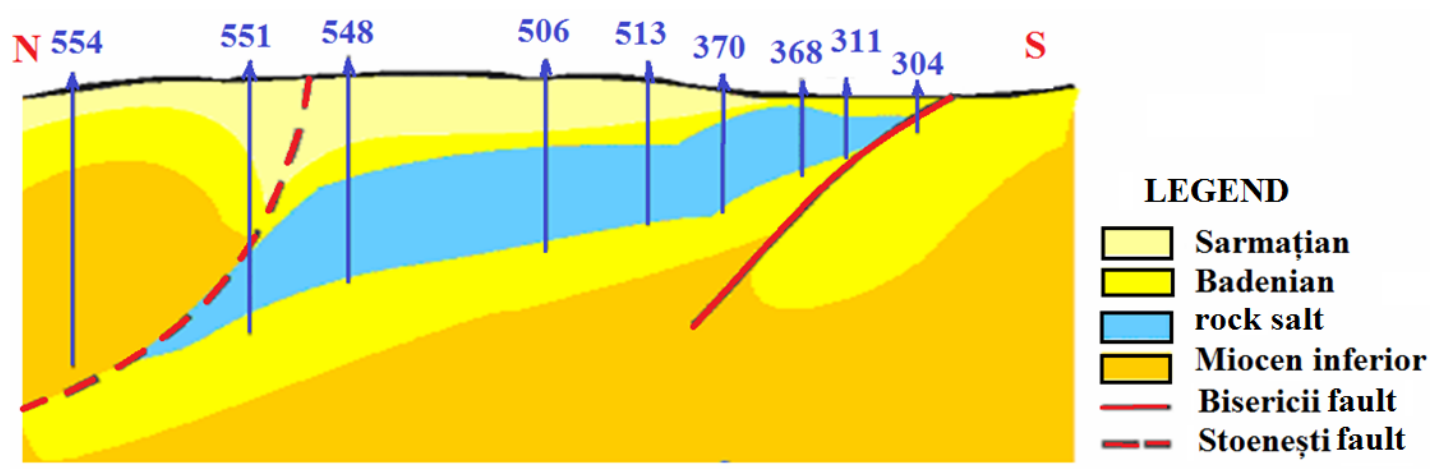

Figure 2. Geological cross section through Ocnele Mari rock salt massif [1]

The thickness of the roof deposits varies between $20 \mathrm{~m}$ and $50 \mathrm{~m}$ in the south and up to 700-800 $\mathrm{m}$ in the north, with the sinking of the deposit. The thicknesses of the rock salt deposit are variable, reaching up to laminations in the north and south, the maximum thickness reaching $450 \mathrm{~m}$ in the central part of the lens.

The rock salt deposit at Ocnele Mari is flanked on the north and south by two major faults, namely: Stoeneşti fault and Bisericii fault. Inside the rock salt massif, the presence of local micro-tectonic phenomena can be noticed.

From a macroscopic point of view, the rock salt from Coceneşti - Ocnele Mari is presented in the form of alternating strips of white rock salt and dark or blackish gray rock salt, contaminated with films and centimetre fragments of marls or anhydrite nests.

The research drillings and mining workings performed were chemically tested along the entire useful length, and the elements analyzed were: $\mathrm{NaCl}, \mathrm{CaSO}_{4}, \mathrm{CaCl}_{2}, \mathrm{MgCl}_{2}, \mathrm{Fe}_{2} \mathrm{O}_{3}$ and insoluble substances.

From the point of view of geological research, no distinction was made in the perimeter of Ocnele Mari. Research - exploration works began in 1952 and intensified between 1988 and 1991.

The rock salt of this deposit has been mined since Roman times, but the systematic exploitation began in the 19th century by bell shape rooms, in the current area of the bathrooms. In 1959, the exploitation of rock salt in the central-western area of the deposit began, through dissolution wells.

The solid way mining of Ocnele Mari - Cocenești rock salt deposit started in 1996, using the mining method with small rooms and square pillars (on a network of $30 \times 30 \mathrm{~m}$ ), in two descending levels, $16 \mathrm{~m}$ high, respectively at the levels $+226 \mathrm{~m}$ and $+210 \mathrm{~m}$ (mined in the period 2001-2020). 
The dimensions of the rooms were $16 \mathrm{~m}$ wide and the pillars $14 \times 14 \mathrm{~m}$, in the west side and $15 \mathrm{~m}$, with pillars $15 \times 15 \mathrm{~m}$, in the east side. The ceiling between the two horizons is $8 \mathrm{~m}$ thick. At present it is opening horizon $+190 \mathrm{~m}$, located under a ceiling of $12 \mathrm{~m}$, by report to the horizon $+210 \mathrm{~m}$. This horizon is designed to be exploited with rooms of $15 \mathrm{~m}$, width and pillars of $15 \times 15 \mathrm{~m}$, on both sides of the mining field.

The values of the land surface elevations are between a minimum $z_{\min }=301 \mathrm{~m}$ and a maximum $z_{\max }=361 \mathrm{~m}$, which corresponds to a variable depth of position of the floor of the horizon $+226 \mathrm{~m}$ of $H=75-135 \mathrm{~m}$.

Taking into account the depth and rate of creep stress of the rock salt $\Delta$, for Ocnele Mari Salt Mine, the constitutive laws of behavior of the rock salt in the underground resistance structures are the following: a) for $H<363 \mathrm{~m}$ - elastic behavior (stability zone, for $\Delta=0,36$ ); b) for $H=363-555 \mathrm{~m}$ - elastic-plastic behavior (relative stability zone, for $0,36<\Delta<0,55$ ); c) for $H>555 \mathrm{~m}$ - elasto-viscous-plastic behavior (instability zone, for $\Delta>0,55$ ).

In the last 50 years, several determinations of geomechanical parameters have been made for the rock salt from Ocnele Mari, the values of which have been used in the calculations on different analytical and numerical models. Over time, the average values of these parameters, most commonly used in calculations, were as follows: apparent specific weight, $\gamma_{a}=2.15 \mathrm{KN} / \mathrm{m}^{3}$; modulus of elasticity, $E=1.5 \cdot 10^{6} \mathrm{KN} / \mathrm{m}^{2}$; Poisson's ratio, $v=0.25$; compressive strength, $\sigma_{c}=21,700 \mathrm{KN} / \mathrm{m}^{2}$; tensile strength, $\sigma_{t}=1,200 \mathrm{KN} / \mathrm{m}^{2}$; shear strength, $\tau_{f}=2,300 \mathrm{KN} / \mathrm{m}^{2}$; cohesion, $C=4,000 \mathrm{KN} / \mathrm{m}^{2}$; internal friction angle, $\varphi=30^{\circ}$ [2].

In general, following the analytical calculations [3] and numerical analyzes [2], [4] performed, it was concluded that the resistance structures (pillars and floors) from the exploited horizons $+226 \mathrm{~m}$ and $+210 \mathrm{~m}$ are stable, taking into account the relatively shallow depth of the mining excavations, and the phenomena of instability are only local and are determined by the inhomogeneities and natural cracks existing in the rock salt massif.

The numerical model with 3D finite element of Ocnele Mari Salt Mine, calculated in the hypothesis of an elasto-plastic behavior without hardening, highlighted on the horizon $+210 \mathrm{~m}$ the east side, a single unstable area with plastic behavior (fig. 3), namely the section area G31-33, related to the 210E directional room. This phenomenon of local instability can be explained by the spatial positioning of the underground mining excavations in relation to the configuration of the deposit and the relief of the land surface, which generated a concentration of stress and strain on this area.

The numerical model with 3D finite element is also validated by the instability phenomena observed in the field, which appeared in the rooms, pillars and the ceiling in the area of the directional room 210E, section G31-33 (presented below).

Figure 4 shows the distribution of the maximum (fig. 4.a) and minimum (fig. 4.b) principal stresses at the level $+210 \mathrm{E}$, with the marking of the area affected by instability in the directional room G31-33, horizon.210E.

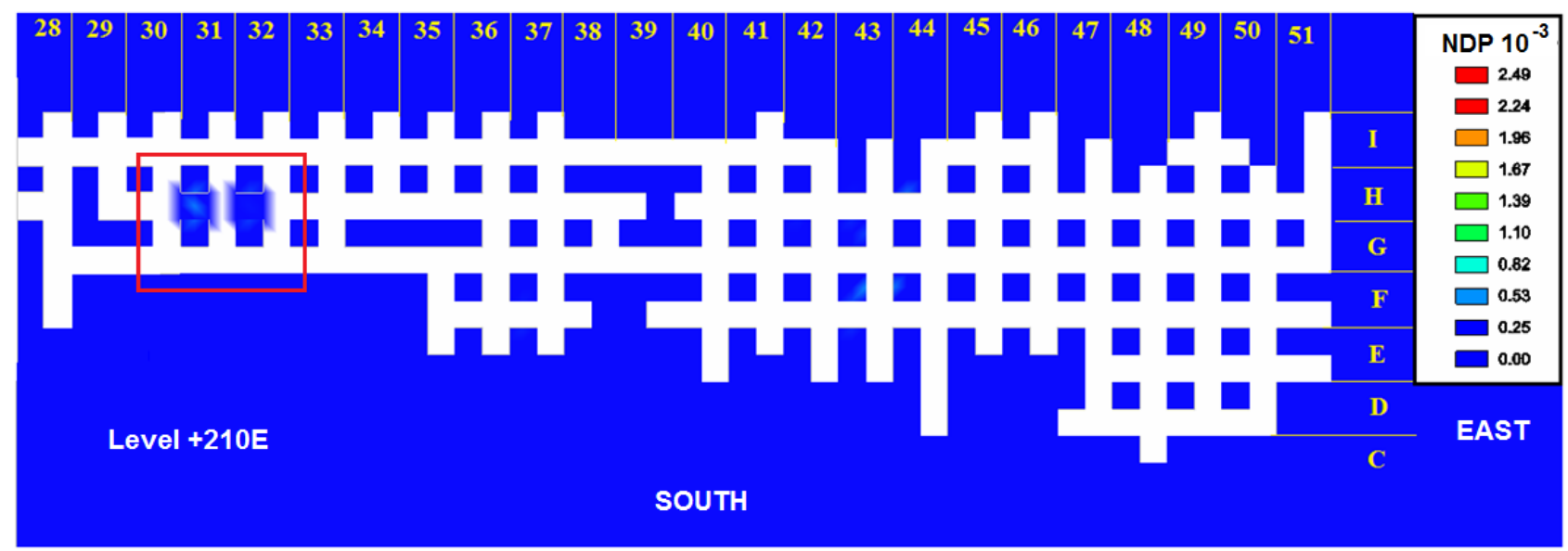

Figure 3. Horizontal view $+210 m$ - eastern side, with scalar representation of plastic deformation norm (NDP) 


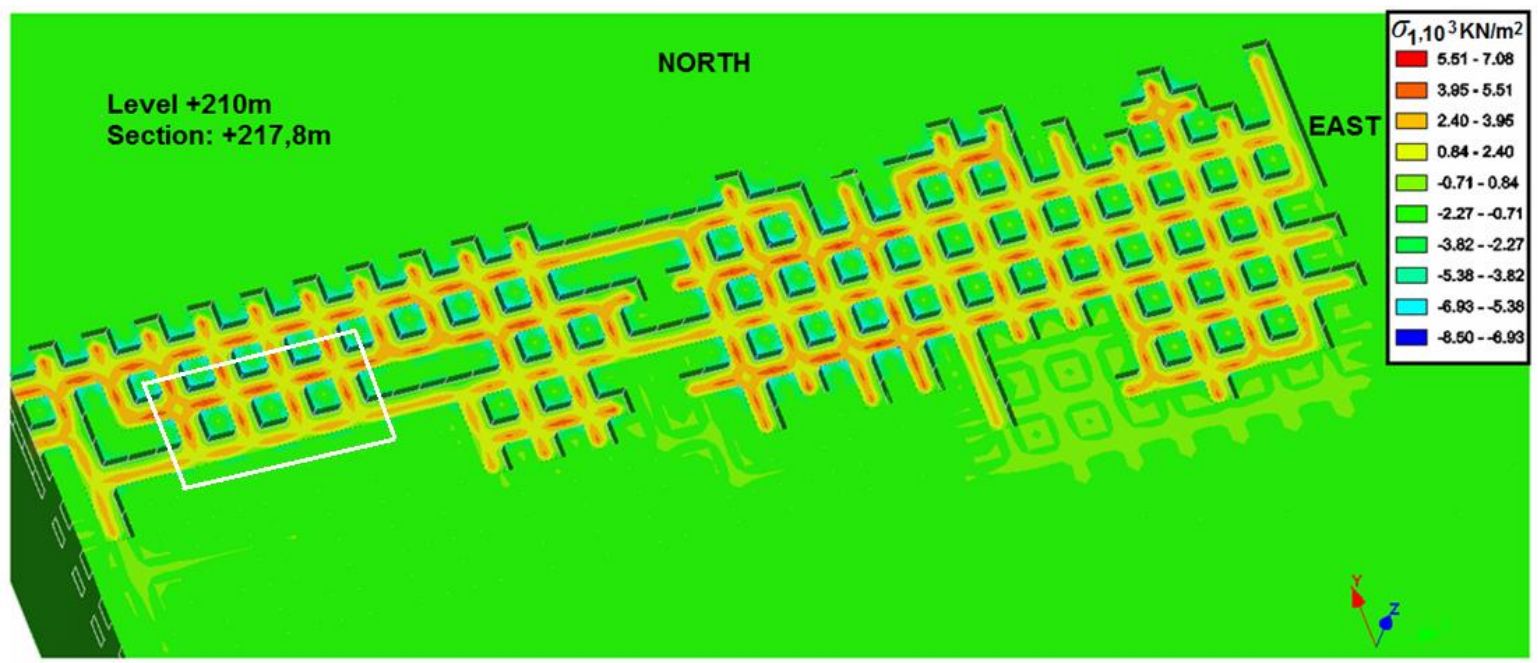

(a)

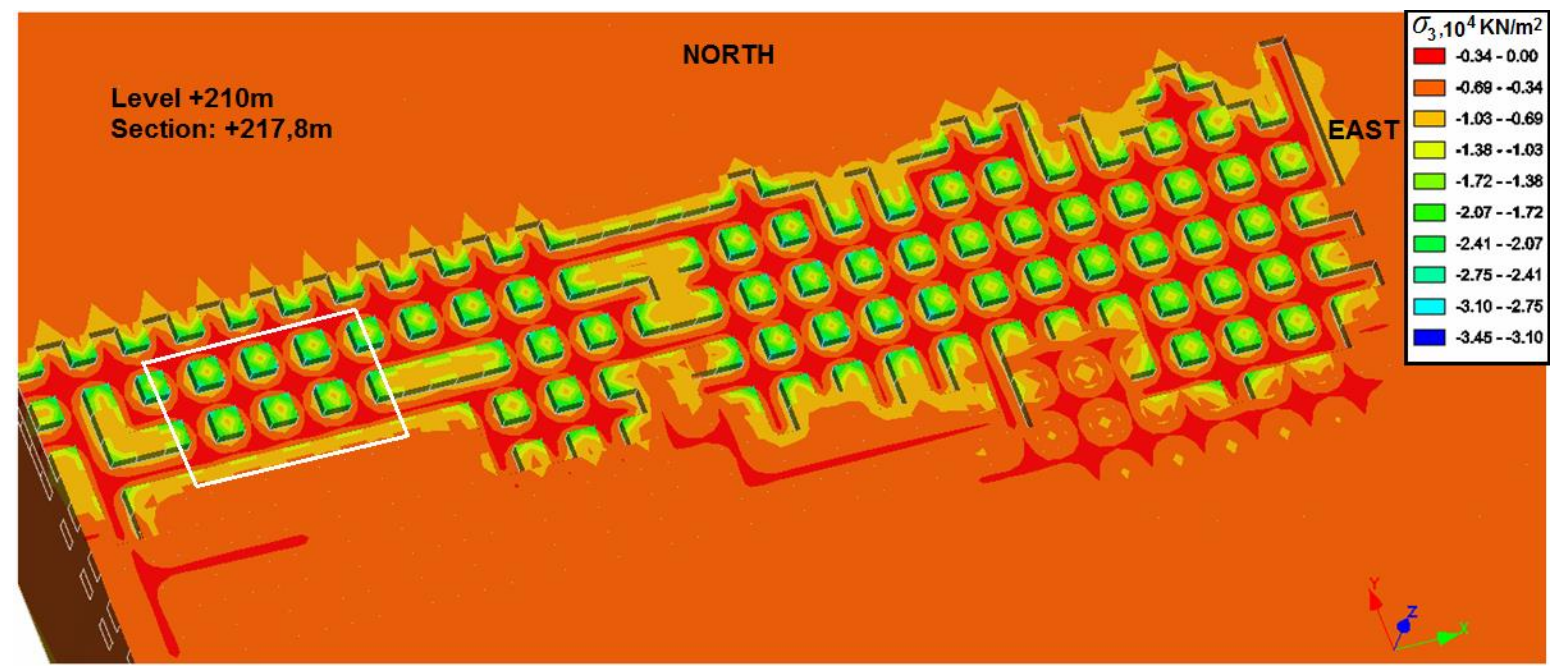

(b)

Figure 4. Horizontal view $+210 \mathrm{~m}$ - eastern side, with scalar representation of the (a) maximum, in $\mathrm{kN} / \mathrm{m}^{2}$ and (b) minimum principal stresses, in $\mathrm{kN} / \mathrm{m}^{2}$

\section{Reinforcement with anchors and shotcrete of the G31-33 directional room, oriz.210E}

The directional mining room $\mathrm{G}$, on the east side, horizon $+210 \mathrm{~m}$, is located at an average depth of $110 \mathrm{~m}$, measured from the land surface, of which approx. $40 \mathrm{~m}$ is represented by the barren rocks of the roof, formed mainly of marls and clays.

The thickness of the crown pillar is $30 \mathrm{~m}$, and from the crown pillar, at a distance of $16-20 \mathrm{~m}$, is the ceiling of the directional room $\mathrm{G}$, where the equipment of the grinding station is located. The G31, G32 and G33 mining rooms are dug entirely in compact rock salt in the middle of the lens. The structure of the rock salt has an inclined stratification, containing sterile centimetre intercalations, of gray clays. The inclination of clay layers and salt banks is variable, in the range of $20^{\circ}-40^{\circ}$.

Following the macroscopic analysis of the walls and ceiling of the mining excavations, after 8 years from the completion of the operation of the rooms, areas with different degrees of stability were identified, the working being framed in an area with potential risk of long-term instability, namely: southern wall of room $\mathrm{G}$ is more stable and without visible signs of degradation; the northern wall is inhomogeneous, being more pronouncedly affected; the ceiling is stable, but exposed to damage due to the state of stress and strain developed in this area.

The section of the directional room 210E, which showed phenomena of contour instability, is located in the area of the mining rooms G31, G32 and G33, horizon + 210E. This section, where consolidation works have already been carried out, completed in 2020 , has a length of: $105 \mathrm{~m}$, in the $\mathrm{G}$ directional room; $7.5 \mathrm{~m}$, in the transverse rooms $\mathrm{G} 31$ and G32;15m, in the room G33 (fig. 5). 


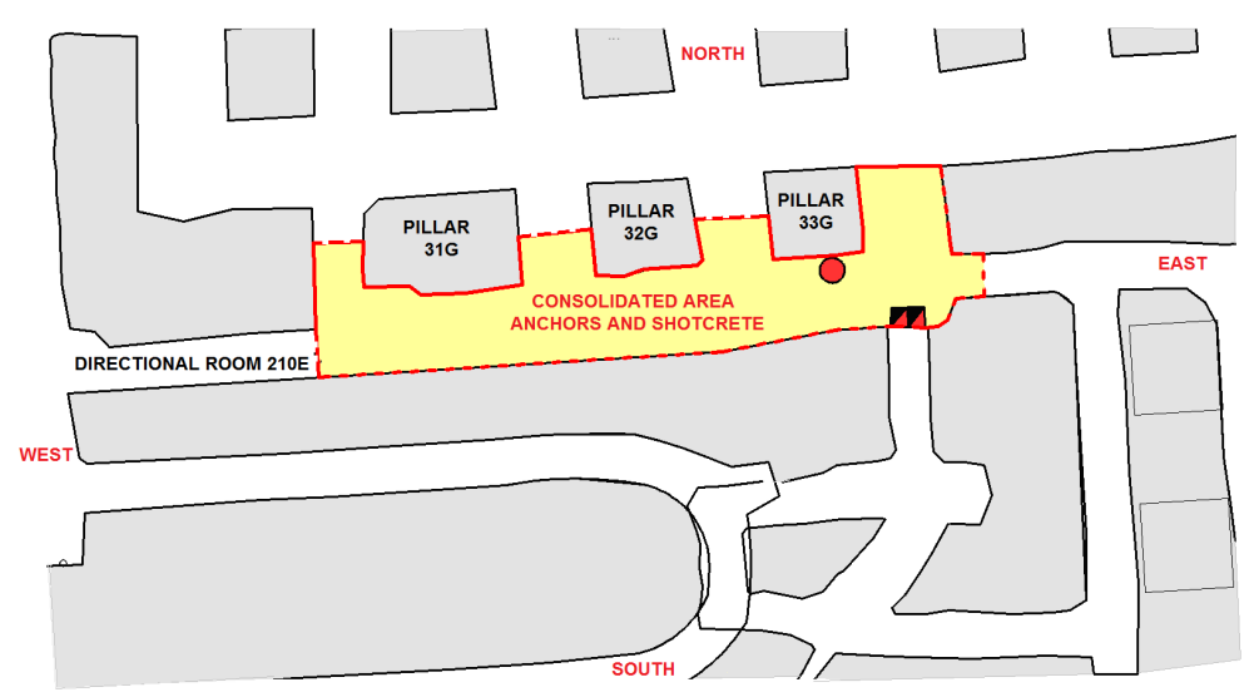

Figure 5. Situation plan of the area of the directional room G, from horizon. 210E, supported by anchors and shotcrete

In this area of the G31-33 directional room, conditions are created for the exfoliation of rock salt on the free surface of the rooms and the formation of different sized exfoliated rock salt, which can endanger the security of personnel. In order to prevent the degradation of the working, the work (Kovacs, 2012) proposed the full coverage of the surface of underground excavations, the treatment of the negative effect of moisture on clay inclusions and the achievement of an efficient support to ensure the operation of mining working for a projected period of over 40 years.

Due to the inclined stratification and the microtrectonics of the rock salt massif, the bolting system arranged on the ceiling and on the northern wall of the directional room cumulatively shows all three types of effects of the bolting support system, namely: the beam effect (by preventing tangential displacements of the stratification strips); the suspension effect (by catching from the intact massif of the blocks with a tendency to detach, generated by the transversal fissures on the stratification); reinforcement effect (by increasing the resistance of the rock salt massif to a depth of $2.5 \mathrm{~m}$, measured from the surface of the excavations) - Brady \& Brown, 2005.

In the project [5], mentioned above, the following underground mining excavations were taken into account in order to be consolidated:

a) directional room G: profile of $15 \times 8 \mathrm{~m}$; consolidated length of $105 \mathrm{~m}$ (90 m west of the collecting bin and $15 \mathrm{~m}$ east of the same bin); ceiling area of $1,575 \mathrm{~m}^{2}$; the surface of the northern wall of $480 \mathrm{~m}^{2}$ and the southern wall of $840 \mathrm{~m}^{2}$;

b) transverse rooms G31 and G32: profile $15 \times 8 \mathrm{~m}$; length of $7.5 \mathrm{~m}$; ceiling area of $225 \mathrm{~m}^{2}$; wall area $240 \mathrm{~m}^{2}$;

c) the transverse room G33, with a length of $15 \mathrm{~m}$ and the other geometric parameters identical to those of the other two transverse rooms, added together.

From the sum of the above areas, resulted a total area, necessary to be consolidated/reinforced, at the level of the ceiling of $2,025 \mathrm{~m}^{2}$ and at the level of the walls of $1,800 \mathrm{~m}^{2}$.

Following the monitoring of the ceiling of the consolidated section of the $210 \mathrm{E}$ directional room, it was proved that the implementation of this project, in 2020, is a successful experiment (as well as the one performed at Ocna Dej Salt Mine, in the transversal gallery $310 \mathrm{~m}$, related to the rooms of the pre-crushing plant), therefore this project can be a model that can be used in similar conditions at Ocnele Mari Salt Mine or other salt mines in Romania.

The anchor and shotcrete support method [6], applied under the conditions of the G31-33 directional room, horizon $+210 \mathrm{E}$ has the following main technical characteristics:

1) The ceiling, in the area where the equipments is located, was supported by anchors (PC52- $\phi 24,2.5 \mathrm{~m}$ long, $1 \mathrm{~m}$ spaced) with a density of 1 anchor $/ \mathrm{m}^{2}$, fixed with LOKSET polyester resins, wire mesh welded (Buzau type) $\mathrm{mm}$, with meshes of $100 / 100 \mathrm{~mm}$ and mechanical shotcrete, with a thickness of $0.1 \mathrm{~m}$; 
2) The north wall and the walls of rooms G31, G32 and G33 were supported with anchors, welded wire mesh and mechanical shotcrete, with a thickness of $0.1 \mathrm{~m}$ (with the parameters

3) The southern wall was supported by a mechanical shotcrete with a thickness of $0.05 \mathrm{~m}$.

The materials used to apply the anchoring/bolting technology are: PC-52 anchors; metal plates; Buzau type metal mesh; corrosion protection materials; LOKSET fixing cartridges with synthetic (chemical) resins.

The PC-52 anchor has a diameter of $24 \mathrm{~mm}$. The front end of the anchor is cut diagonally at an angle of $45^{\circ}$, and the other end is threaded with M20,150 mm long. The threaded portion of the anchors was protected against corrosion with an ICOSIT POXICOLOR epoxy resin. The plate is made of OL 35 steel sheet, square in shape, with a side of $150 \mathrm{~mm}$, provided in the center with a hole of $\phi 22 \mathrm{~mm}$. Buzău type $\phi 8 \mathrm{~mm}$ welded wire mesh, with $100 \times 100 \mathrm{~mm}$ mesh, is made of $2 \times 4 \mathrm{~m}$ panels.

The technology of mounting the support with anchors and shotcrete (fig.6) consists of the following successive operations: a) scaling the exfoliated surface, b) drilling holes for anchors, with a length of $2.5 \mathrm{~m}$ and a diameter of $28 \mathrm{~mm}$, according to the support monograph; c) preparation of the package with LOKSET chemical fixing cartridges; d) preparation of the metal anchor and the P90 perforator, with the telescopic column; e) inserting into the hole of 1.5 pieces LOKSET HS Slow ampoules, $500 \mathrm{~mm}$ long and $24 \mathrm{~mm}$ in diameter; f) inserting the anchor to the bottom of the hole, so that the $5-10 \mathrm{~cm}$ threaded portion remains outside the hole, followed by fixing it in the hole with 2 wedges and leaving an interval of 24 hours to strengthen the synthetic resin; g) mounting the plastic plate, the metal mesh (without touching the rock salt massif) and the metal plate which, then, will be tightened with the M20 nut, at a moment of $20 \mathrm{kgf} \cdot \mathrm{m}$, using a torque wrench; h) anti-corrosion protection of the anchor thread with Mapeter resin; i) application of shotcrete with a thickness of $0.1 \mathrm{~m}$, after an interval of 48 hours.

Shotcreting was done in successive layers 2-3 cm thick, with the help of an ALIVA 240.5 shotcreting machine.

The formula for shotcrete mortar is as follows: Portland I cement $42.5-600 \mathrm{~kg} / \mathrm{m}^{3}$; sand sort $0-3 \mathrm{~mm}-0.4$ $\mathrm{m}^{3}$; sand sort 3-7 mm - $0.4 \mathrm{~m}^{3}$; gravel 7-15 mm - $0.3 \mathrm{~m}^{3}$; grip accelerator (Sigunit or Bara Gunit) $-33 \mathrm{~kg}$; water - 200-250 1 .

Prior to the formation of the final layer of shotcrete, a layer of blocking shotcrete was applied directly to the surface of the rock salt massif, with the following formula: Portland I cement $42.5-600 \mathrm{~kg} / \mathrm{m}^{3}$; sand sort $0-3 \mathrm{~mm}-1.1 \mathrm{~m}^{3}$; socket accelerator $-33 \mathrm{~kg}$; salt water $0.15-0.25 \mathrm{~kg}$ salt $/ 1$.

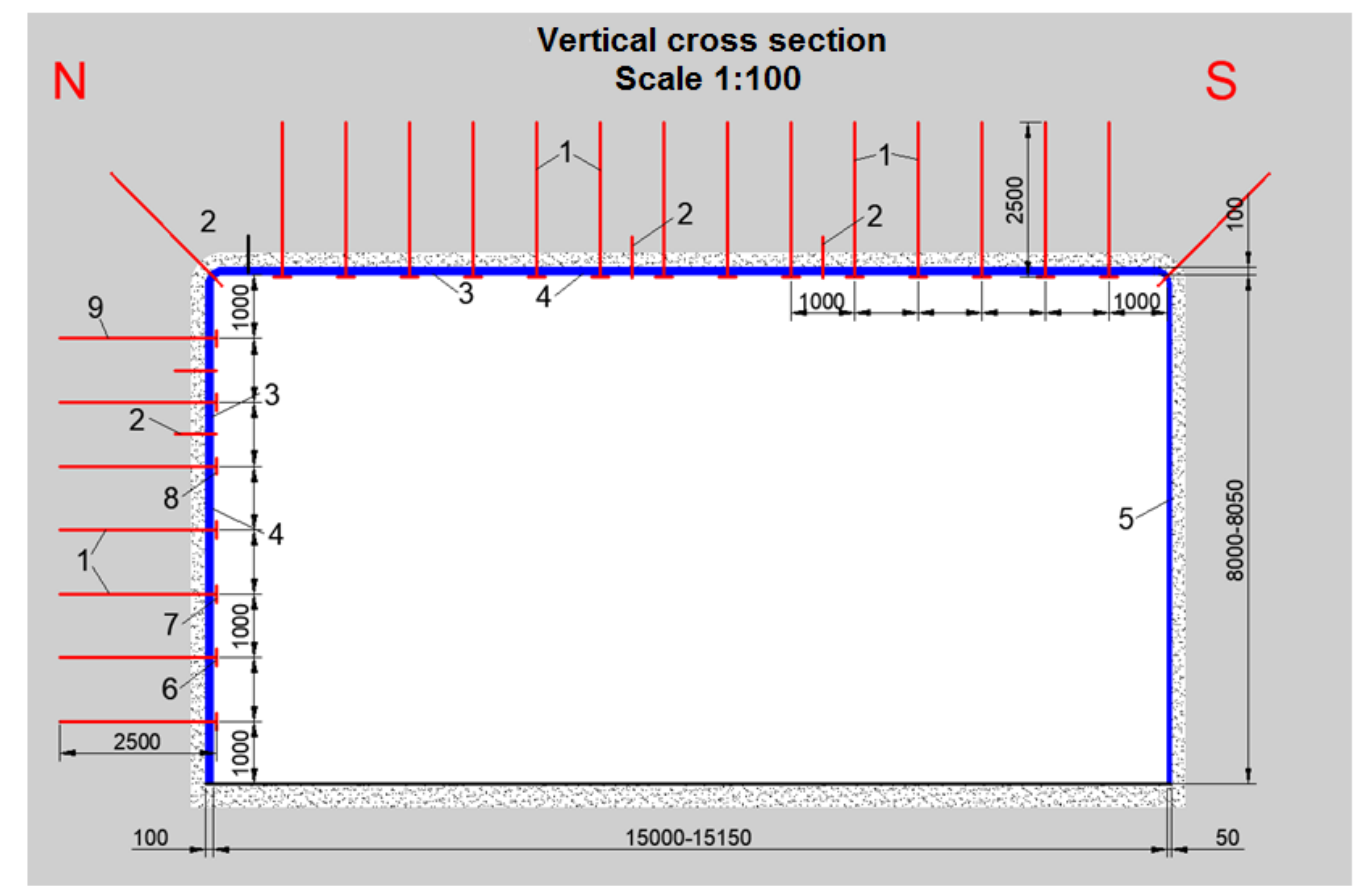

Figure 6. Cross section through directional room $+210 \mathrm{E}$, with layout of anchors / bolts on the contour of the mining workings [5]

1-bearing anchor; 2-mesh tension anchors: 3-wire mesh; 4-reinforced shotcrete; 5-single shotcrete; 6- plastic plate; 7-anchor plate; 8-nut M20; 9-ampoule of polyester resins 


\section{Topographic monitoring of the displacements of the ceiling of the directional room G31-33, horizon} $210 \mathrm{E}$

In December, 2020, 24 topographic landmarks were placed on the ceiling of the G31-33 directional room, horizon 210E, in the area of the underground grinding plant of Ocnele Mari Salt Mine, an area supported by anchors and shotcrete. The objective of the topographic landmarks was to monitor the movements of the salt block that tends to detach from the ceiling of the room, and the first measurement was performed on 15.12.2020.

To perform the measurements, a "measuring base" consisting of points $210^{\mathrm{E}}$ and terminal B1, located on the floor of the directional room $210 \mathrm{E}$, was established. For these two points, topographic measurements were performed in the particular reference system of the mine, determining the coordinates $\mathrm{Y}$ (after the direction $\mathrm{W}-\mathrm{E}), \mathrm{X}(\mathrm{N}-\mathrm{S})$ and $\mathrm{Z}$ (after the vertical). Starting with the points of the measurement base, measurements were performed on the 24 landmarks, with the help of the total station Leica -TS 06, using its measurement function without prism, determining the $\mathrm{X}, \mathrm{Y}$ and $\mathrm{Z}$ coordinates of each landmark. In June 2021, the second measurement was performed. The time interval between the first and second measurements was 6 months. Following the measurements, the horizontal displacements $\Delta \mathrm{X}$ and $\Delta \mathrm{Y}$ and the level differences $\Delta \mathrm{Z}$ were calculated, so that the vertical displacements and the rate of displacements of the ceiling surface of the underground excavation were obtained.

Given the very short interval (only 6 months) between the two measurements and the relative accuracy of the measurements, we consider that at this stage the results are not relevant. As the time interval between the first and subsequent measurements increases, significant conclusions can be drawn about the evolution of the monitored mining deformation phenomenon over time and a number of forecasting functions can be developed.

However, a concentration of vertical displacements towards the $31 \mathrm{G}$ pillar area of max. $10-15 \mathrm{~mm}$ (fig. 7.a), of the horizontal displacements along the $\mathrm{X}$ axis, in the area of the $31 \mathrm{G}$ and $32 \mathrm{G}$ pillars, of max. 3-5 mm and less towards the $33 \mathrm{G}$ pillar (fig.7.b) and of the horizontal displacements along the $\mathrm{Y}$ axis, of max. $8-10 \mathrm{~mm}$, at the limit with the $31 \mathrm{G}$ pillar and with the room between this pillar and $32 \mathrm{G}$ (fig.7.c).

Even if the monitoring period is irrelevant, a concentration of the deformations of the ceiling of the directional room $210 \mathrm{E}$ can be found in the area of the pillars and towards the corner between the pillars and the ceiling of the mining working. These observations are in full agreement with the concentration of stresses on the row of pillars located in the immediate vicinity of the monitored working.

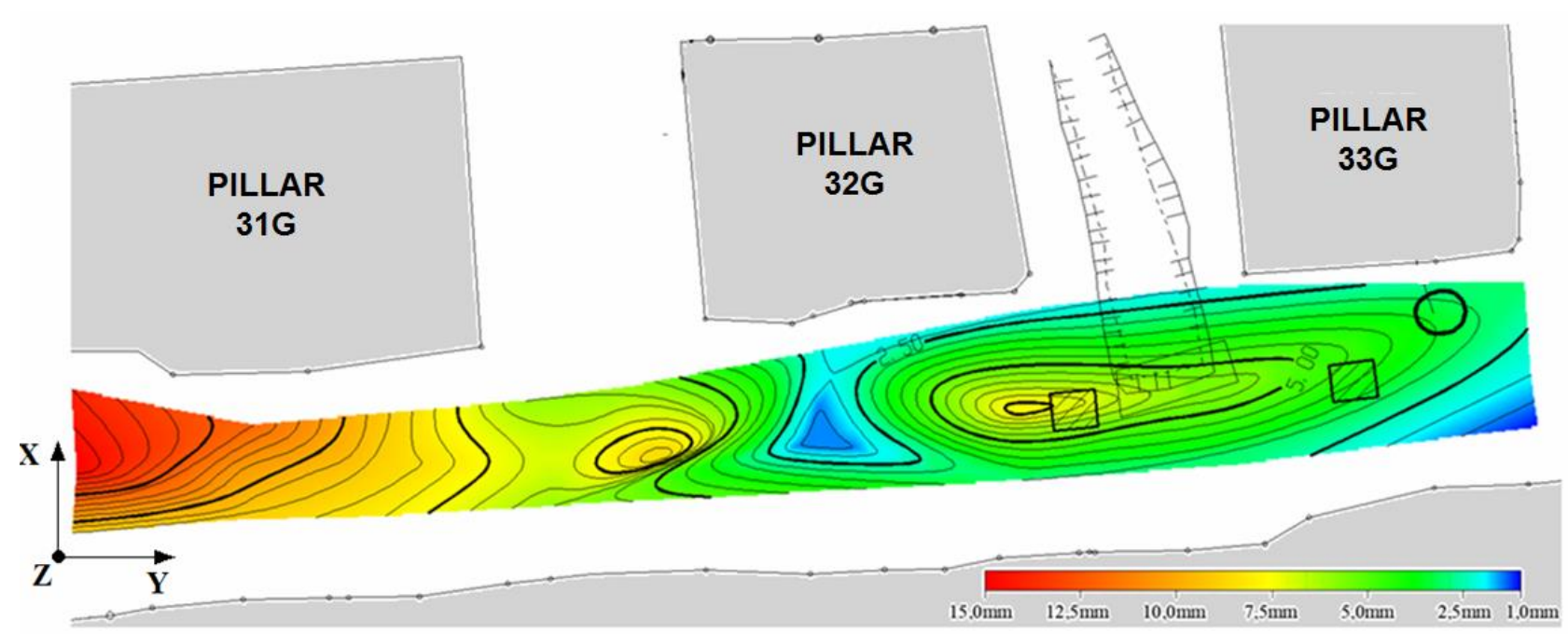

a) 


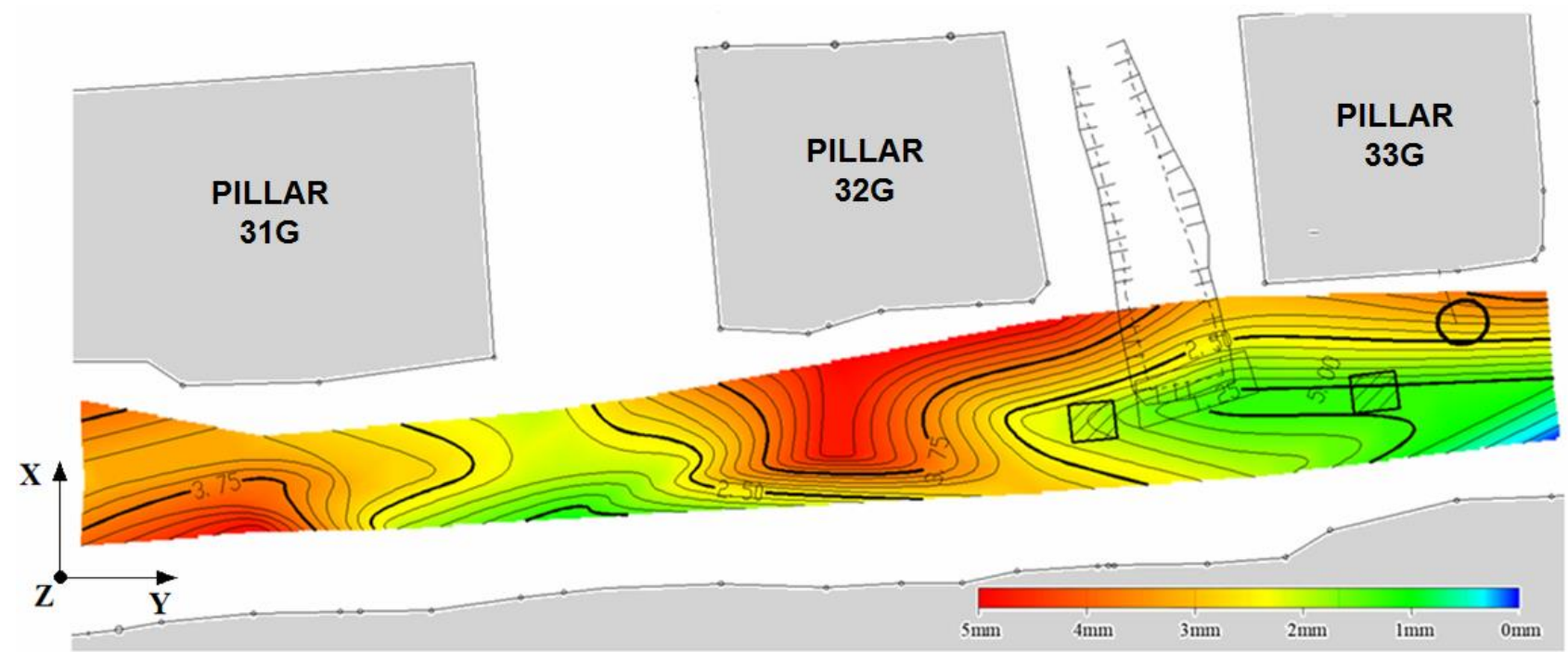

b)

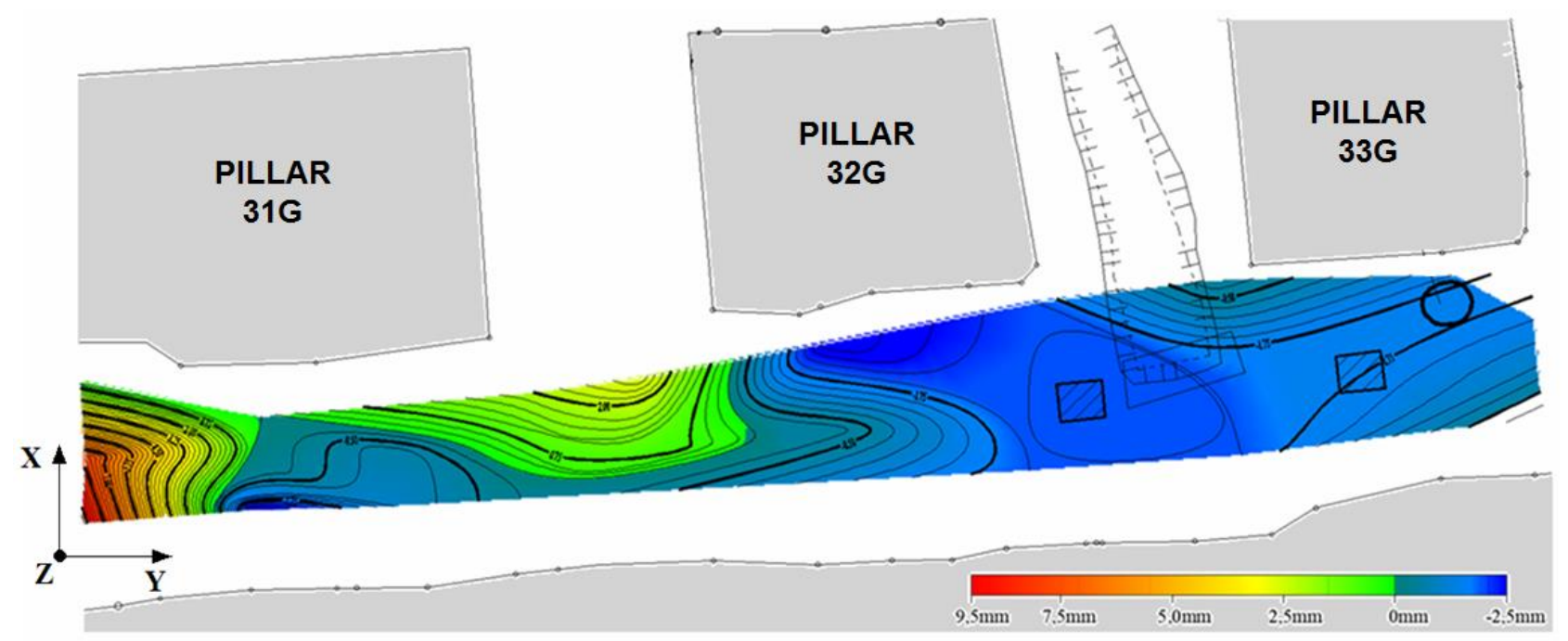

c)

Figure 7. (a) Vertical along the $\mathrm{Z}$ axis, (b) horizontal along the $\mathrm{X}$ axis and (c) horizontal, along the $\mathrm{Y}$-axis displacements of the ceiling of the directional room $210 \mathrm{E}$, June, 2021 - scalar representation

\section{Conclusions}

Following the calculations performed by analytical methods and the analyzes by numerical methods, it was proved that the underground mining excavations and the resistance structures from Ocnele Mari-Cocenești Salt Mine are stable.

There are phenomena of local instability generated by inhomogeneity and natural fissures in the rock salt massif or due to the local concentration of stress and strain, due to the relative spatial position of the mining excavations from the two exploited horizons, $+226 \mathrm{~m}$ and $+210 \mathrm{~m}$, in relation with the configuration of the deposit and the relief of the land surface.

An area affected by instability is the G31-33 directional room, horizon $+210 \mathrm{E}$, where a series of cracks and exfoliations were found on the contour of the excavations. This area was also highlighted in numerical 3D models, by the presence of the phenomenon of rock salt plasticization and by the concentration of stresses in this area.

The area of the G31-33 directional room, horizon 210E, was reinforced by support with $2.5 \mathrm{~m}$ long cemented anchors and reinforced shotcrete. 
Following the monitoring of the displacements of the ceiling of the consolidated directional room, an obvious stabilization of it was found and a distribution of the maximum vertical and horizontal displacements in the areas of the stress concentrators in the vicinity of the pillars.

\section{References}

[1] Marica D., 2011

Study of the stability of mining excavations at the Ocnele Mari salt mine in order to increase the degree of work safety, $\mathrm{PhD}$ thesis, University of Petroșani.

[2] Onica, I., Cozma, E., Marica, D.P., 2011

Stability Analysis of the Rock Salt Rooms and Pillars of the Ocnele Mari Saline with the Aid of the 2D Finite Element Modelling, Annals of the University of Petroşani, Mining Engineering, Vol.12 (XXXIX), pag.7-17.

[3] Hirian, C., Georgescu, M., 2012

Stability of old salines in Romania - condition of their use for various fields, Universitas Publishing House, 2nd Edition, 2012.

[4] Onica, I., Marian, D.P., 2016

Applications of the finite element method in the analysis of stability of grounds and underground structures, Ed. Universitas, Petroşani.

[5] Kovacs, F., 2012

Minimal flow of grinding rock salt in the underground of the Ocnele Mari Salt Mine, Râmnicu Vâlcea Mining Branch. Volume II - Consolidation of the area of the grinding flow. Technical project phase and specifications, Symbol 3/4/2012, S.C. DACITROM SRL Cluj-Napoca.

[6] Brady, B.G.H., Brown, E.T., 2005

Rock Mechanics for underground mining, Third edition, Kluwer Academic Publishers, New York, Springer Science + Business Media, Inc.

This article is an open access article distributed under the Creative Commons BY SA 4.0 license. Authors retain all copyrights and agree to the terms of the above-mentioned CC BY SA 4.0 license. 